Gut, 1981, 22, 927-932

\title{
Role of mucosal prostaglandins and DNA synthesis in gastric cytoprotection by luminal epidermal growth factor
}

\author{
S J KONTUREK*, T BRZOZOWSKI, I PIASTUCKI, A DEMBINSKI, T RADECKI, \\ A DEMBINSKA-KIEC, ANNA ZMUDA, AND H GREGORY \\ From the Institute of Physiology and Pharmacology, Academy of Medicine, Krakow, Poland, \\ and Research Department, ICI Pharmaceutical Division, Alderley Park, \\ Macclesfield, Cheshire
}

SUMMARY This study compares the effect of epidermal growth factor and prostaglandins (PGE $\mathrm{P}_{2}$ or $\mathrm{PGI}_{2}$ ), applied topically to gastric mucosa, on gastric secretion and formation of ASA-induced gastric ulcerations in rats. Epidermal growth factor given topically in non-antisecretory doses prevented dose-dependently the formation of ASA-induced ulcers without affecting prostaglandin generation but with a significant rise in DNA synthesis in the oxyntic mucosa. The anti-ulcer effect of topical prostaglandins was also accompanied by an increase in DNA synthesis. This study indicates that topical epidermal growth factor, like $\mathrm{PGE}_{2}$ or $\mathrm{PGI}_{2}$, is cytoprotective and that this cytoprotection is not mediated by the inhibition of gastric secretion or prostaglandin formation but related to the increase in DNA synthesis in oxyntic mucosa.

Epidermal growth factor (EGF) is a single chain of 53 amino acid residues which inhibits gastric acid secretion and stimulates epithelial cell proliferation. ${ }^{2} \mathrm{~A}$ hypothetical role for EGF is protection of the gastrointestinal mucosa, as it is produced by salivary and duodenal glands ${ }^{3}$ and may be secreted into the gut lumen. So far only prostaglandins (PGs) have been thought to be capable of protecting the mucosa against chemical or thermal injury and this property, termed 'cytoprotection', has been regarded as a unique feature of PGs. ${ }^{4}$

This study was designed to compare the gastric secretory and cytoprotective effects of EGF and PGs applied topically to the gastric mucosa against aspirin-(ASA) induced mucosal lesions and to elucidate the possible role of $\mathrm{PG}$ formation and DNA synthesis in the action of EGF on gastric mucosa.

\section{Methods}

Wistar rats, weighing 150-200 g, were used for the studies on gastric secretion, gastric ulcer production,

*Address for correspondence: Professor SJ Konturek, Institute of Physiology, 31-531 Kraków. ul. Grzegórzecka 16, Poland.

Received for publication 7 May 1981 prostaglandin generation, and DNA synthesis in the oxyntic mucosa.

\section{SECRETORY STUDIES}

Ten rats were prepared with chronic gastric fistulae, as described by Lane and Ivy, ${ }^{6}$ and used for the secretory studies. Experiments started about one month after surgery. Rats were allowed only water for at least 24 hours and were kept in individual metabolic cages to prevent coprophagia. In the morning, animals were placed in restraining Bollman cages, the gastric fistula was opened, and the stomach washed out with tap-water. The tests were conducted with seven to 10 day intervals between successive experiments on the same animal. Gastric secretion was collected at half-hourly intervals in the graduated tubes, the volume was noted, and hydrogen ion concentration was determined by titration to pH 7.0 with $0.1 \mathrm{~N} \mathrm{NaOH}$ using an automatic titrator (Radiometer, Copenhagen) and ion output was expressed in $\mathrm{mmol} / 30 \mathrm{~min}$. Pepsin content was also measured in each sample using Anson's haemoglobin method ${ }^{7}$ and expressed in $\mathrm{mg} / 30 \mathrm{~min}$.

Two series of secretory studies were performed, one under basal conditions and another after pentagastrin stimulation. Basal gastric secretion 
was collected during three 30 minute periods and then EGF, $\mathrm{PGE}_{2}$, or $\mathrm{PGI}_{2}$ was instilled into the stomach in a dose of $100 \mu \mathrm{g} / \mathrm{kg}$ and the gastricfistula was closed for 25 minutes. After this interruption, the fistula was opened again, the stomach drained for five minutes, and this collection discarded. The collection was then continued for another 90 minutes with saline infused subcutaneously at a rate of $4 \mathrm{ml} / \mathrm{h}$ throughout. In another series of tests, pentagastrin was infused subcutaneously at a rate of $200 \mu \mathrm{g} / \mathrm{kg}$ per h throughout the experiment. The collection of gastric juice and the administration of EGF, PGE.2, or PGI. was similar to the tests with basal secretion. All secretory tests were performed on the same 10 gastric fistula rats.

PRODUCTION OF GASTRIC ULCERS

Gastric mucosal lesions were produced by intragastric instillation of aspirin (ASA) plus $0.15 \mathrm{M}$ $\mathrm{HCl}$ as described by Kauffman and Grossman." For this purpose, rats were surgically prepared with a polyethylene tube in the stomach about two hours before the experiment. The intragastric instillation of ASA as a bolus injection of $60 \mathrm{mg} \mathrm{kg}$ was followed by a constant infusion of $42 \mathrm{mg} / \mathrm{kg} / \mathrm{h}$ for three hours. A simultaneous gastric perfusion with $0 \cdot 15$ $\mathrm{M} \mathrm{HCl}$ was carried out at a rate of $4 \mathrm{ml} / \mathrm{h}$. In tests with epidermal growth factor or prostaglandins, the solution of these compounds was injected intragastrically 30 minutes before and continued throughout ASA administration. At the end of the experiment, the animals were killed, the stomach was removed and opened along the greater curvature. The mucosa was quickly examined, the surface area of ulcers was measured planimetrically $\left(\mathrm{mm}^{2}\right)$ and the mucosal biopsy samples were taken for determinations of PG and DNA.

Studies were performed on groups of eight to 30 rats, fasted 24 hours, and given one of the following intragastric treatments: (1) saline (control); (2) epidermal growth factor; (3) PGE.2; (4) $\mathrm{PGI}_{2}$; (5) ASA + $\mathrm{HCl}$; (6) ASA - HCl $\cdot \mathrm{EGF}$; (7) $\mathrm{ASA}_{\rightarrow} \mathrm{HCl}: \mathrm{PGE}_{2}$; and (8) ASA $-\mathrm{HCl}_{2} \mathrm{PGI}_{2}$. As the animals receiving combinations $1-4$ did not show ulceration, their stomachs were used only for the prostaglandin generation and DNA synthesis. In rats with five to eight treatments the mean ulcer area was also measured.

Solutions of epidermal growth factor and prostaglandins were freshly prepared before the experiment. EGF or PGE.2 was dissolved in saline and kept at room temperature, whereas $\mathrm{PGI}_{2}$ was dissolved in isotonic Tris buffer ( $\mathrm{pH} \mathrm{9.6)} \mathrm{and} \mathrm{kept}$ in ice throughout the infusion. Epidermal growth factor was isolated from mouse submaxillary glands according to the method of Savage and Cohen ${ }^{9}$ with minor modifications. The product, a single peak on Bio Gel P-6, had a correct amino acid ratio and was homogeneous on acrylamide gel electrophoresis. It strongly inhibited histamine stimulated acid secretion from the dog Heidenhain pouch and was equipotent with highly purified urogastrone. Both prostaglandins were a gift from Dr J Griffith of Upjohn Co (Kalamazoo, Michigan). Epidermal growth factor was given in a bolus intragastric injection of 1,10 , or $100 \mathrm{ug} / \mathrm{kg}$ and then infused intragastrically in a supporting, 10 times smaller dose $(0 \cdot 1,1$, or $10 \mathrm{ug} / \mathrm{kg} / \mathrm{h}$ respectively) for 3.5 hours either alone or in combination with acidified ASA added to the infusion 30 minutes after the start of EGF administration. PGE, or PGI. was given first as an intragastric bolus injection of $100 \mathrm{ug} / \mathrm{kg}$ and this was continued by intragastric infusion of $10 \mathrm{ug} / \mathrm{kg} / \mathrm{h}$ for 3.5 hours either alone or in combination with ASA as in tests with EGF.

MEASUREMENT OF MUCOSAL

GENERATION OF PGS

Assessment of the capacity of oxyntic mucosa to generate prostaglandins was determined by the method of Whittle ${ }^{10}$. Generation was measured by a quick extraction and immediate bioassay, $\mathrm{PGE}_{2}$ and $\mathrm{PGF}_{2 \alpha}$ by using superfused biological detectors - that is, strips of rat stomach and colon ${ }^{11}$-and $\mathrm{PGI}_{2}$ by using its anti-aggregatory activity in rabbit platelet-rich plasma. ${ }^{12}$ The amounts of the generated PG were expressed in $\mathrm{ng} / \mathrm{g}$ tissue weight.

DETERMINATION OF DNA SYNTHESIS

DNA synthesis in the oxyntic mucosa was measured by in vitro incubation of fundic mucosa in Eagle's minimal essential culture medium containing 2 $\mu \mathrm{Ci} / \mathrm{ml}\left[{ }^{3} \mathrm{H}\right]$-thymidine (Amersham, England) as described previously. ${ }^{13}$ The incorporation of $\left[{ }^{3} \mathrm{H}\right]-$ thymidine into DNA was determined by counting $0.5 \mathrm{ml}$ of the DNA-containing filtrate in a Beckman liquid scintillation counting system. Results were calculated as disintegrations per min (DPM) per mg of wet weight and expressed as DPM per $\mu \mathrm{g}$ DNA. The DNA of the samples was determined by the Burton ${ }^{14}$ procedure modified by Giles and Myers. ${ }^{15}$

Plasma salicylate levels in animals treated with intragastric ASA were measured in the blood samples taken from the inferior vena cava at the end of the experiment using Saltzman's method. ${ }^{16}$

All values reported are the means (: SEM). These means were used in the $t$ test for paired values to evaluate the significance of differences in gastric secretory outputs, ulcer area, prostaglandin generation, and DNA synthesis in gastric mucosa 
between control groups and treated with EGF, $\mathrm{PGE}_{2}$, or $\mathrm{PGI}_{2}$. As used in the text, significance indicates $\mathrm{P}<0.05$.

\section{Results}

EFFECT OF EGF AND PGS ON GASTRIC SECRETION

Figures 1 and 2 show the effects of epidermal growth factor in a dose of $100 \mu \mathrm{g} / \mathrm{kg}$ on acid and pepsin secretion. This factor did not significantly affect gastric secretion either under basal conditions or after pentagastrin stimulation. $\mathrm{PGE}_{2}$ and $\mathrm{PGI}_{2}$ given intragastrically in a dose of $100 \mu \mathrm{g} / \mathrm{kg}$ did not influence gastric acid or pepsin secretion and these results were omitted from the presentation.
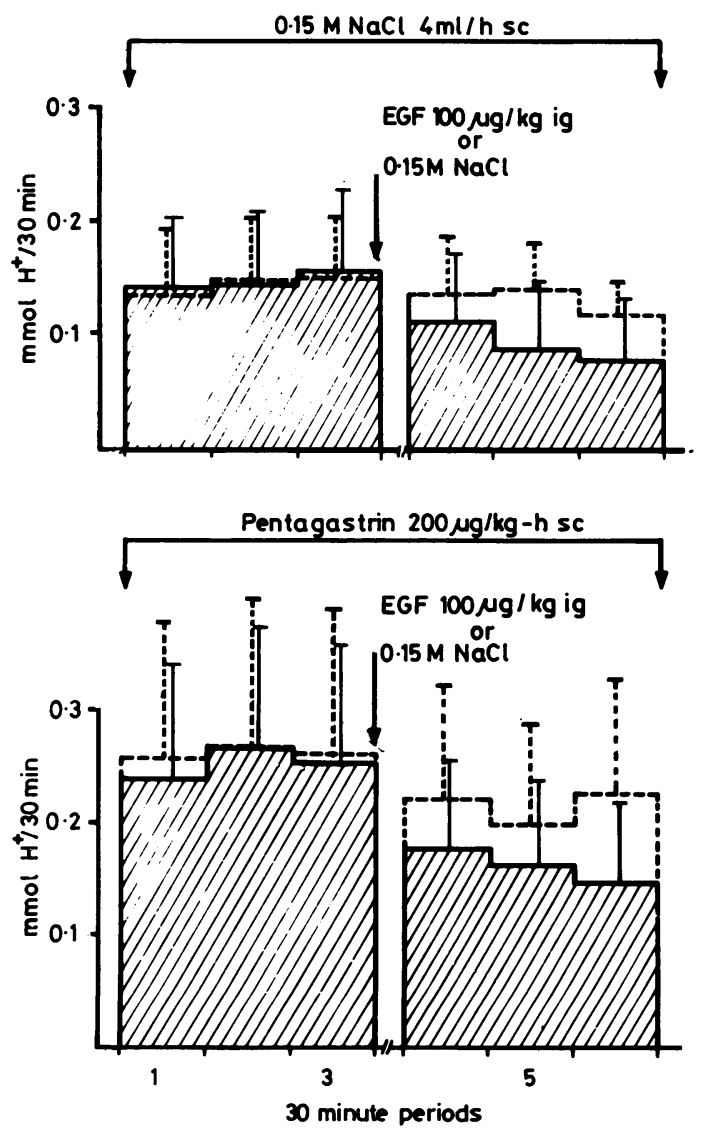

Fig. 1 Effect of intragastric administration of EGF (hatched) or saline (control) (dotted lines) on basal and pentagastrin stimulated acid secretion from 10 gastric fistula rats. Mean $\pm S E M$ of 10 experiments.
EFFECT OF EGF AND PGS ON PG GENERATION AND DNA

Synthesis in intact rats

In rats given only intragastric saline, the $\mathrm{PGE}_{2}$ and $\mathrm{PGI}_{2}$ were generated in the oxyntic mucosa in amounts of about $446 \pm 148$ an $271 \pm 129 \mathrm{ng} / \mathrm{g}$, respectively (Fig. 3). The generation of $\mathrm{PGF}_{2}$ was negligible and the data were not included. DNA synthesis in the intact mucosa was about $56 \pm 4$ DPM $\left[{ }^{3} \mathrm{H}\right]$-thymidine/ $\mu \mathrm{g} \quad \mathrm{DNA}$ and this was accepted as $100 \%$ control. Epidermal growth factor instilled intragastrically in a dose of 100 $\mu \mathrm{g} / \mathrm{kg}$ followed by intragastric infusion of $10 \mu \mathrm{g} /$ $\mathrm{kg} / \mathrm{h}$ for 3.5 hours did not significantly affect the generation of $\mathrm{PGE}_{2}$ or $\mathrm{PGI}_{2}$ but increased DNA synthesis in oxyntic mucosa by approximately $35 \%$ (Fig. 4). When a test infusion of $100 \mu \mathrm{g} / \mathrm{kg} \mathrm{PGE}$ or $\mathrm{PGI}_{2}$ was given intragastrically the generation of prostaglandins was not determined because the samples were contaminated with exogenous PGs. DNA synthesis was not affected by this treatment of oxyntic mucosa and the data were omitted from the presentation.

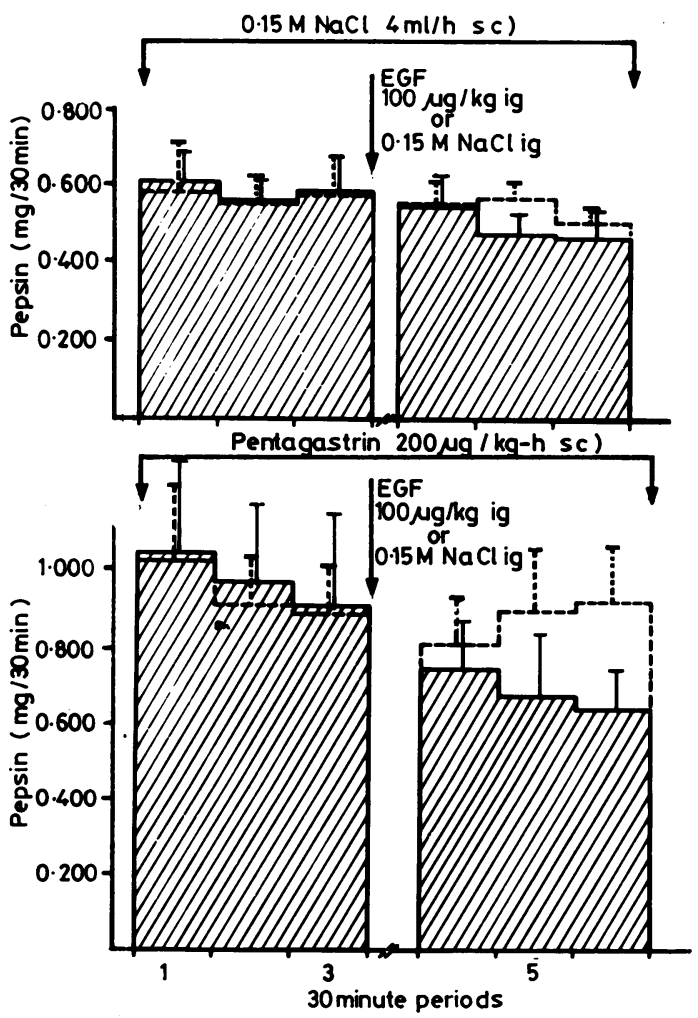

Fig. 2 Pepsin outputs in test as in Fig. 1. (Key as in Fig. 1.) 
EFFECTS OF EGF AND PGS ON

GASTRIC ULCER FORMATION, PG

GENERATION, AND DNA SYNTHESIS IN

ASA-TREATED RATS

All 30 control rats treated with intragastric instillation of ASA plus $\mathrm{HCl}$ developed gastric ulcers that occurred mainly in the oxyntic gland areathe mean ulcer area was $7 \cdot 65 \pm 0.91 \mathrm{~mm}^{2}$ (Fig. 5). Epidermal growth factor given intragastrically 30 minutes before and throughout intragastric infusion of acidified ASA caused a dose dependent reduction in the mean ulcer area. This reduction in the ulcer area by EGF at doses of 1,10 , and $100 \mu \mathrm{g} / \mathrm{kg}$ was about $55 \%, 72 \%$, and $85 \%$, respectively. $\mathrm{PGE}_{2}$ or $\mathrm{PG}_{2}$ in a dose of $100 \mu \mathrm{g} / \mathrm{kg}$ caused similar reduction in the ulcer area to that achieved by EGF in a dose of $100 \mu \mathrm{g} / \mathrm{kg}$.

ASA instilled intragastrically in combination with $\mathrm{HCl}$ reduced the generation of $\mathrm{PGE}_{2}$ in oxyntic mucosa by about $80 \%$ and caused the almost complete disappearance of $\mathrm{PGI}_{2}$. The generation of prostaglandins in animals treated with a combination of acidified ASA plus epidermal growth factor in a dose of $100 \mu \mathrm{g} / \mathrm{kg}$ was not significantly different from that observed in animals receiving ASA alone (Fig. 3).



Fig. 3 Generation of $P G E_{2}$ and $P G I_{2}$ in oxyntic mucosa of intact rats infused intragastrically with saline, epidermal growth factor, acidified $A S A$ alone, or in combination with epidermal growth factor. Each column represents mean \pm SEM of results fiom eight to 30 rats.
The effects of EGF, $\mathrm{PGF}_{2}$, or $\mathrm{PGI}_{2}$, all given intragastrically in a bolus dose of $100 \mu \mathrm{g} / \mathrm{kg}$, followed by infusion of $10 \mu \mathrm{g} / \mathrm{kg}$ for 3.5 hours, on DNA synthesis in ASA-treated rats are shown in Fig. 4. The intragastric administration of ASA plus $\mathrm{HCl}$, which caused the formation of mucosal lesions, significantly depressed DNA synthesis by

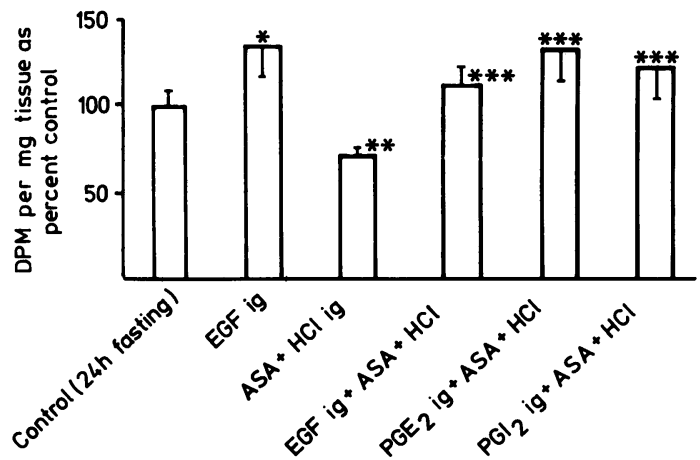

Fig. 4 DNA synthesis in oxyntic mucosa of rats treated with topical epidermal growth factor alone and acidified $A S A$ alone or in combination with EGF, $P G E_{2}$, or $P G I_{2}$. Each column represents mean $\pm S E M$ of results from eight to 30 rats. ${ }^{*}$ Significant $(P<0 \cdot 5)$ increase above control level. **Significant decrease below the control level. ***Significant increase above the level found in rats treated with acidified $A S A$.

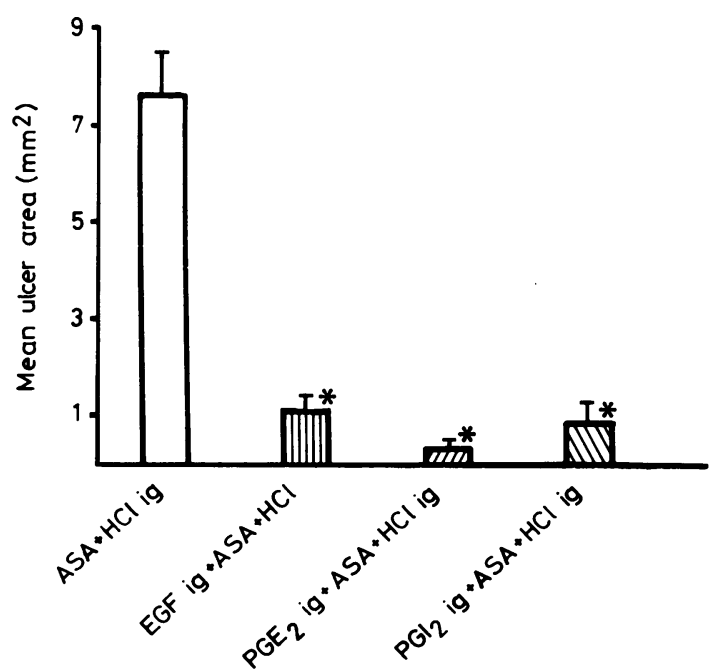

Fig. 5 Mean ulcer area in animals treated with intragastric acidified ASA alone or in combination with epidermal growth factor, $P G E_{2}$, or $P G I_{2}$. Each column represents mean $\pm S E M$ of results from eight to 30 animals. * Significant decrease below the value obtained in rats treated with acidified ASA. 
about $28 \%$. Pretreatment with EGF, $\mathrm{PGI}_{2}$, or $\mathrm{PGE}_{2}$ significantly raised DNA synthesis in the gastric mucosa to a level similar to that observed in control animals.

Plasma salicylate levels in rats receiving only intragastric ASA plus $\mathrm{HCl}$ averaged $396 \pm 47 \mu \mathrm{g} / \mathrm{ml}$ and it was not significantly different in animals receiving epidermal growth factor or prostaglandins. These data are not included for the sake of clarity.

\section{Discussion}

The results show that epidermal growth factor is capable of preventing ASA-induced gastric ulcerations and the effect is not related to inhibition of gastric secretion or prostaglandin generation but to DNA synthesis in oxyntic mucosa.

The formation of gastric lesions has been attributed to a mucosal deficiency of prostaglandins because of the known irreversible inactivation of the PG synthetase system by ASA. ${ }^{17}$ This notion is supported by our findings that ASA almost completely suppresses the generation of prostaglandins in oxyntic mucosa and that $\mathrm{PGE}_{2}$ and $\mathrm{PGI}_{2}$, which are the major products of the biotransformation of arachidonate via the cyclo-oxygenase pathway in the rat gastric mucosa ${ }^{18}$ are capable of preventing the development of ASA-induced ulcers. ${ }^{4}{ }^{5} 18$ The protective effects of exogenous $\mathrm{PGE}_{2}$ and $\mathrm{PGI}_{2}$ against ASA-induced mucosal lesions could be explained by the replenishment of the mucosal level of these compounds. Thus, normal generation of mucosal $\mathrm{PGE}_{2}$ and $\mathrm{PGI}_{2}$ appears essential for the protection of gastric mucosa against chemical injury by ASA. ${ }^{18}$ This action of prostaglandins does not appear to be mediated through the inhibition of gastric secretion (cytoprotection) as natural prostaglandins were used topically and these were found to be without any influence on basal or pentagastrin-induced gastric acid or pepsin secretion.

Although gastric cytoprotection was claimed to be a unique property of prostaglandins, ${ }^{4}$ our study provides evidence that epidermal growth factor is also cytoprotective when applied topically in a dose which does not affect gastric secretion. It appears that topical EGF neither affects the prostaglandin generation in the intact mucosa nor prevents the suppression of this generation in ASA-treated animals. This rules out the possible mediation of mucosal prostaglandins in the cytoprotective action of EGF.

The major finding is that pretreatment with acidified ASA decreases DNA synthesis with gastric ulceration and EGF reverses this change in DNA synthesis. The reason for the reduction in DNA synthesis by ASA is unknown but it may be due to destruction of large numbers of mucosal cells, possibly because of the removal by ASA of the cytoprotective function of mucosal prostaglandins. Indeed, topical administration of exogenous prostaglandins in a non-antisecretory dose prevents the fall in DNA synthesis while protecting the mucosa against ulcer formation. Thus, the common action of both epidermal growth factor and prostaglandins is the prevention of DNA synthesis which renders the oxyntic mucosa more resistant to the ulcerogenic effect of acidified ASA.

It may be worthwhile to mention that a similar reduction in DNA synthesis in the gastric mucosa of animals with stress-induced gastric ulcerations has been reported..$^{19}{ }^{20}$ The application of trophic substances such as growth hormone ${ }^{19}$ or pentagas$\operatorname{trin}^{20}$ prevented the formation of these lesions and this effect was also closely correlated with an increase in DNA synthesis.

This study demonstrates that epidermal growth factor is cytoprotective after topical application to the gastric mucosa when the inhibitory effect of the peptides is entirely excluded. This indicates that the antisecretory and growth-promoting actions of EGF are two independent features of this peptide. As EGF is produced by the salivary and duodenal glands and may be released into the gut lumen, it may serve as a natural growth-promoting factor for the mucosa, and is also responsible for its protection against injury by various noxious agents. Thus, the gastrointestinal mucosa is provided with at least two separate cytoprotective mechanisms, one related to the local generation of prostaglandins and another involving the release and action of epidermal growth factor.

\section{References}

${ }^{1}$ Cohen S, Savage CR. Recent studies on the chemistry and biology of epidermal growth factor. Recent Prog Horm Res 1974; 30 : 551.

${ }^{2} \mathrm{Gregory} \mathrm{H}$. Isolation and structure of urogastrone and its relationship to epidermal growth factor. Nature 1975; 257 : 325-7.

${ }^{3}$ Gregory $\mathrm{H}$, Bower JM, Willshire IR. Urogastrone and epidermal growth factor. FEBS Colloq 1978; 48: 75-84.

'Robert A, Nezamis JE, Lancaster C, Hanchar AJ. Cytoprotection by prostaglandins in rats: prevention of gastric necresis produced by alcohol, $\mathrm{HCl}, \mathrm{NaOH}$, hypertonic $\mathrm{NaCl}$ and thermal injury. Gastroenterology' 1979; 77: 433-43.

${ }^{5}$ Robert A. Cytoprotection and prostaglandins. Gastroenterology 1979; 77: 761-7.

${ }^{6}$ Lane A, Ivy AC. Response of the chronic gastric fistula rat to histamine. Am J Phy'siol 1957; 190: 221-8.

'Anson ML. The estimation of pepsin, trypsin, papain and cathepsin with hemoglobin. J Gen Physiol 1938; 22: 78-89. 
${ }^{8}$ Kauffman GL, Grossman MI. Prostaglandin and cimetidine inhibit the formation of ulcers produced by parenteral salicylate. Gastroenterology 1978; 75: 1099-102.

${ }^{9}$ Savage CR, Cohen S. Epidermal growth factor and a new derivative. Rapid isolation procedures and biological and chemical characterization. $J$ Biol Chem 1972; 247: 7609-11.

${ }^{10}$ Whittle BJR. Potential endogenous inhibitor of prostaglandin synthetase in plasma failure to inhibit cyclooxygenase in platelets and the gastric mucosa. J Pharmacol Pharmac 1978; 30: 467-8.

${ }^{11}$ Vane JR. The use of isolated organs for detecting active substances in the circulating blood. Br J Pharmacol Chemother 1964; 23: 360-73.

${ }^{12}$ Gryglewski RJ, Bunting S, Moncada S, Vane JR. Arterial walls are protected against deposition of platelet thrombi by a substance (prostaglandin X) which prevents platelet aggregation. Prostaglandins 1976; 12: 685-9.

${ }^{13}$ Johnson LR, Guthrie P. Effect of cholecystokinin and 16, 16-dimethylprostaglandin $E_{2}$ on RNA and DNA of gastric and duodenal mucosa. Gastroenterology 1976; 70: 69-5.
${ }^{14}$ Burton K. A study on the conditions and mechanism of the diphenylamine reaction for the calorimetric estimation of deoxyribonucleic acid. Biochem J 1956; 62: 315-23.

${ }^{15}$ Giles KW, Myers A. An improved diphenylamine method for the estimation of deoxyribonucleic acid. Nature 1965; 206: 93.

${ }^{16}$ Saltzman A. Fluorophotometric method for the estimation of salicylate in blood. J Biol Chem 1948; 74: 399-404.

${ }^{17}$ Vane JR. Inhibition of prostaglandin synthetase as a mechanism of action for aspirin-like drugs. Nature 1971 ; 231 : 232-5.

${ }^{18}$ Konturek SJ, Piastucki I, Brzozowski T, Radecki T, Dembinska-Kiec A, Zmuda A, Gryglewski R. Role of prostaglandins in the formation of aspirin-induced gastric ulcers. Gastroenterology 1981; 80:4-9.

${ }^{19}$ Takeuchi K, Johnson LR. Pentagastrin protects against stress ulcerations in rats. Gastroenterology 1979; 76: 327-34.

${ }^{20}$ Vanamee P, Winawer SJ, Sherlock P. Decreased incidence of restraint-stress induced gastric erosions in rats treated with bovine growth hormone. Proc Soc Exp Biol Med 1970; 135: 259-62. 